\title{
Guidelines for the publication of manuscripts in Salud Pública de México
}

\section{Objectives}

Salud Pública de México is an international, bi-monthly publication by the Instituto Nacional de Salud Pública (National Institute of Public Health INSP in Spanish); it is indexed and has peer review. The journal's general purpose is to disseminate information on public health, which is understood as the application of the biological, social and administrative sciences to the analysis of health phenomena in human populations, as well as the identification of health needs and the organization of integrated services. ${ }^{1}$ The journal's specific objectives are to review historical experiences and stimulate new currents of thought in the health field; to participate in the debate over changes in health conditions and in the organized social response to such conditions; and to serve as a forum where all innovations in the field of public health and related areas can be discussed, with the greatest possible rigor.

The INSP grants editorial independence to the director of Salud Pública de México, who adheres to the guidelines established by the World Association of Medical Editors.

Salud Pública de México is indexed in Current Contents/Social and Behavioral Sciences, Social Sciences Citation Index, Research Alert, Index Medicus, Index Medicus Latinoamericano, Excerpta Medica, Índice de Revistas Científicas Mexicanas de Excelencia del Consejo Nacional de Ciencia y Tecnología, Bibliomex Salud, Periódica, Índice de Revistas de Educación Superior e Investigación Educativa (IRESIE), and in the online systems Medline and Lilacs, as well as in the CD Artemisa. At present it is distributed in Mexico and abroad among professionals and technicians in the field of public health.

\section{Legal aspects and general criteria for publication}

In proposing articles for publication, the authors accept the conditions contained in the current guidelines and transfer the copyright of the article in question to Salud Pública de México for editing, publishing, reproducing, disseminating, and commercial purposes, as well as for translating or authorizing the translation of the article into any language. The rights transferred include the publication of the article in all forms, including print, magnetic, or electronic, or in all other forms or by any means of dissemination that exist or that may be developed in the future, as well as producing publications through the total or partial concession of licenses to third parties.

Salud Pública de México reserves all copyrights of articles accepted for publication. All or part of the material published in the journal may be reproduced provided express permission has been obtained, in writing, from Salud Pública de México, and provided that the source is cited.

All proposed articles must be original and not previously published, and may not be submitted to any journal while under consideration by Salud Pública de México. Complete articles previously published in summarized form may also be accepted, and unpublished papers presented at conferences or seminars.

All articles shall be published with the full knowledge of the authors.

Signed articles are the responsibility of the authors and do not necessarily reflect the opinion of the journal, of the National Institute of Public Health, or of the institution to which the author is affiliated. 


\section{Specific criteria for publication and the selection process}

Salud Pública de México is a bilingual journal that publishes articles in Spanish and in English only on subjects of public health and related areas. The journal does not undertake translations of the articles and only publishes the articles in the original language (Spanish or English) in which they are submitted for evaluation.

Criteria for selection include scientific soundness, originality, topicality and timeliness of the information. In addition, the journal gives priority to original articles with research findings over reviews and essays. These two latter types of work are received, preferentially by direct invitation from the journal.

Articles that the Editorial Committee consider pertinent are submitted for peer review. The complete process includes:

- A first review, which is the responsibility of the editors, determines the manuscript's importance, relevance and depth, and also whether or not it corresponds to editorial guidelines, complies with the norms of Salud Pública de México and meets the general criteria for publication.

- A second review, which is entrusted to at least two experts. In the event that they are not in agreement, the article is submitted for consideration by the Editorial Committee or, alternatively, an additional evaluation is requested.

The decision may be acceptance, rejection, or conditional acceptance subject to modifications suggested by the reviewers.

All decisions are communicated exclusively to the author, in writing, within a period of two to three months from the date of receipt of the original manuscript. If the article is subject to conditional acceptance, the new version must be sent within the stated period, but in no case may it exceed 30 days.

\section{Content of Salud Pública de México}

The material sent to Salud Pública de México is published in the form of editorials, original articles, brief articles, reviews, essays, updates, classics, indicators, news, book reviews, letters to the editor, and articles on special topics. The journal also includes announcements of scientific activities and publications provided these are requested in writing. In exceptional cases, the journal accepts translations of works originally published in another language, if the subject-matter is of interest to Spanish-language readers.
Subject Areas. Salud Pública de México receives articles on all topics related to public health, in the broadest sense, as well as those related to epidemiology.

Editorial. This is an opinion section. It consists of reflections on topical matters, comments about articles or about the journal itself. The title of the editorial should not be long and complex, since the text itself is short. Generally, the use of subtitles is not recommended. The author's institutional affiliation should be presented below the author's name, which will appear at the end of the text. If references are used, they should follow the same format and style as for the articles.

Original articles. This section includes findings from original research projects and not descriptive articles. The structure is as follows: Introduction, material and methods, results and discussion. At the beginning of each article, abstracts and key words are included, in both Spanish and English; the maximum number of tables and figures, combined, is five.

Brief articles. This section includes articles limited to 1000 words, plus two tables and/or figures, and an abstract limited to 100 words. Such articles present preliminary or collateral findings that merit further research or that support decision-making in health services. Moreover, they will be evaluated in the context of local or current conditions of known studies. The presentation must meet the same guidelines for content and rigorous scientific standards that apply to longer articles.

Review articles. Although, in general, this type of article is received preferentially by invitation, interested authors shall meet the following requirements: the article must be developed with the participation of a leader in the subject matter under investigation; it must correspond to a topic that is relevant to public health and indicate the period of time that the work covers; it must be exhaustive with respect to the objective stated, which should be precise and be included at the beginning of the article, and it should include the quantity of articles considered and the data or sources consulted; the article should include an introduction, discussion and conclusions, as well as an abstract and key words in Spanish and English; the number of pages must not exceed 18 , including references, and the number of tables and figures, combined, is a maximum of five; the discussion and conclusions must be based on, and propose research actions that open new avenues for the solution of the public health problem.

Essays. This section includes writings devoted to a critical examination and reflection on topics related to public 
health that follow the same format and style as review articles, but it is recommended that they be shorter in length. This type of article is generally received at the expressed request of Salud Pública de México; however, those interested may send proposals which will be reviewed by the Editorial Committee.

In all cases, essays must meet quality criteria similar to that of review articles; they must encompass a topic relevant to public health and be exhaustive with respect to the analysis and description of the arguments that support the conclusions.

Classics. This section reproduces articles that, owing to their influence in the field of public health, have become required references.

Indicators. These are current and relevant statistical information for the public-health area; they include epidemiological and health data and indicators, presented principally in graphic form through tables and figures. In this section, authorship is institutional rather than individual.

Newws. This section will report on the results of events that, because of their importance, may be of interest to the development of scientific knowledge.

Updates. Descriptive articles whose objective is to present the elements that make known the state of the art of the research in a particular area of public health. They should include recent information offering the reader an updated overview of the area in question.

Public health pages. These are book reviews, comments, or brief notes on recent scientific developments in public health and related areas.

Letters to the editor. This section's purpose is to stimulate a feedback process that allows an evaluation and, if applicable, a redefinition of editorial policy and product of Salud Pública de México. This section also serves as a forum for the open discussion of topics presented in the journal and other matters of interest. The letters must contain the title, text, author's name and institutional affiliation and, if applicable, references.

Articles on special topics. These are documents that do not fit into any of the above-mentioned categories, but, because of their content, are of interest to public health researchers and academics. Such documents may comprise reproductions or, even, translations of other work or articles previously published in other academic media or scientific journals.

\section{Instructions for the presentation of manuscripts}

All papers submitted for publication should be in electronic form in Word format. If postal delivery is preferred, the manuscript must, in addition, be sent in print and in duplicate, include tables and figures, and be printed on white, letter-sized paper $(21 \times 28 \mathrm{~cm})$, singlefaced and double-spaced. (The content of one page is approximately 25 lines and 65 characters per line.) The correspondence should be sent to: Editor Ejecutivo, $\mathrm{Sa}$ lud Pública de México, Av. Universidad 655, Santa María Ahuacatitlán, 62508 Cuernavaca, Morelos, México. If you would like to send your work electronically, please send it to: spm@correo.insp.mx. In all cases, we request that you send the original, signed submission letters to us at our physical address; by fax to: (777) 329-3000 ext. 6426; or by e-mail as an attachment.

It is essential that all work be accompanied by a cover letter stating the following:

1. Títle of the article.

2. Approval of the contents of the article (including tables and figures) and the order of authorship, which will be considered definitive with no exception.

3. Acceptance of the transfer of rights to Salud Pública de México, in the event that the article is published.

4. Explicitly name the ethics committee that approved the investigation protocol, and for cases that involve working with subjects clearly indicate that written informed consent was obtained.

5. Declaration that the article is an original work that has not been published or simultaneously submitted for publication, either partially or totally, by the authors themselves or any other authors, to any other national or foreign journal or media, in printed or electronic form.

6. The names and signatures of all of the authors.

Moreover, the letter must specify the author responsible for correspondence and reprint requests, as well as information for communications (institutional affiliation, complete postal address, telephone and fax numbers, and e-mail address).

Original articles and reviews must not be shorter than 10 pages or longer than 18 pages (with a maximum of 4000 words) from the initial page up to and including references, tables and figures are considered separately. In the case of essays, a length less than that for original and review articles is advised.

Authors should keep a copy of all material sent, as articles submitted for review are not returned, regardless of whether or not they are published. 
The manuscript's components should observe the following structure:

- Front page (title, authors, institutional affiliation, data for reprint requests)

- Abstracts and key words (in English and Spanish)

- Text

- Declaration of conflicts of interest

- Acknowledgments

- References

- Tables and figures

\section{A. Front page}

The front page must contain the work's complete title, written in a clear and precise manner, as well as the suggestion for a short title not exceeding five words. Next, a list with the full names of the authors in the order in which they are to appear in the publication; it is important for this order to be definitive, as it cannot be modified subsequently. Each author's academic degrees must be specified, as well as his or her institutional affiliation. Salud Pública de México recommends a maximum of six authors for original articles and three for essays and reviews; when the number is greater it is necessary to include a justification that clarifies the contribution of each author in the development of the article submitted, and not necessarily in the research project. Even when the number of authors adheres to the recommendations, such justification may be requested when the Editorial Committee deems it appropriate. In this regard, it is worth noting that these guidelines meet the requirements of the International Committee of Medical Journal Editors, ${ }^{2}$ which set forth:

Authorship will be credited solely on the basis of the writer's essential contribution as to: a) conception and design of the study, or analysis and interpretation of the data; b) the writing of the article or the critical revision of a part of its intellectual content; and c) final approval of the version to be published. Requirements $\mathrm{a}, \mathrm{b}$ and $\mathrm{c}$ must always be fulfilled. Participation that consists merely in obtaining financing or collecting data does not justify granting anyone authorship. Neither does general supervision of the group of researchers suffice. Any part of the article that is essential to the main conclusions should be the responsibility of at least one of the authors.

In an article by a corporate (collective) author, those persons who are chiefly responsible for the document must be specified; all other individuals who have collaborated in the work will be acknowledged in a separate section (see "Acknowledgments").
The journal's editors may request the authors to justify the attribution of authorship. It is important to point out that when information generated by other institutions is used, either independently or jointly, authors must request the necessary permission and give credit to the corresponding source.

\section{B. Abstract in English and key words}

On the second page of the manuscript, an abstract in English must be presented; in the case of original and brief articles, the abstract should be structured so as to indicate specifically: objective, materials and methods, results and discussion (most relevant conclusions). In the case of review articles and essays, abstracts should also reflect the structure of such types of articles (introduction, discussion, and conclusions). All articles must provide three to six key words to make possible rapid identification of the article's subject-matter; for choice of key words, the controlled vocabulary used by the following indexes of descriptors is recommended: Medical Subject Headings, of Index Medicus; Descriptores en Ciencias de la Salud, of the Red BIREME, and Bibliomex Salud, of the UNAM/SSA/IMSS. Abstracts should be limited to 150 words in the case of original articles and 100 words for brief articles.

\section{Title, abstract and key words in Spanish}

The third page corresponds to the translation into Spanish of the title of the article and the abstract. If necessary, it may be longer than the original abstract, since it is important that it contains sufficient information so that the Spanish-language reader knows the fundamental data in the article. The translation of the key words should also be included. The suggested length is 150 and 100 words for original and brief articles, respectively.

\section{Text}

This part of the article should begin on the fourth page of the manuscript. When the article deals with research reports, the text should contain the following sections:

Introduction. The author must state the purpose of the work and some of the historical facts that the study is based on.

Materials and methods. This section will include the selection procedures of the experimental material utilized (human or animal) and will identify the methods, equipment and procedures in sufficient detail to permit their reproduction. All procedures carried out in humans 
should conform to the ethical norms on human experimentation established by the Helsinki Declaration of 1975. All articles shall indicate the informed consent of the participants in the study and the authorization of the corresponding committee. On no account will the persons who participated in the study be identified. The drugs and chemical products used should be indicated, including their generic names, dosage and means of administration. The mathematical procedures and statistical methods should be described in detail.

Results. Findings will be presented following a logical sequence, both in the text and in the tables and figures. Data displayed in the tables and figures should not be repeated in the text; here, authors will only comment on or summarize the most important observations. The total number of tables and figures (combined) should not exceed five.

Discussion. In this section authors will highlight the study's most innovative and important aspects of the study and will set forth the conclusions. Data presented in the section on results should be summarized. Results are usually compared here with those of similar studies. Assertions and conclusions not supported by the research findings presented should be avoided.

\section{E. Conflict of Interest Statement}

According to the manual Uniform requirements for manuscripts submitted to biomedical journals: Writing and editing for biomedical publications, by the International Committee of Medical Journal Editors, a conflict of interest exists "when an author (or the author's institution), reviewer, or editor has financial or personal relationships that inappropriately influence (bias) his or her actions (such relationships are also known as dual commitments, competing interests, or competing loyalties)" ${ }^{3}$

These Uniform requirements identify the financial relationships in various ways, as "the most easily identifiable conflicts of interest and the most likely to undermine the credibility of the journal, the authors, and of science itself." ${ }^{3}$

Therefore, Salud Pública de México, in accordance with the guidelines by The Cochrane Collaboration, ${ }^{4}$ as well as the manual by the International Committee of Medical Journal Editors, requires that the authors of research articles, principally, but also of other types of writing, include with the submission letter a conflict of interest statement, in which it is made explicit whether or not an economic, personal, political or academic relation exists that could influence their judgment. In particular, if they "have received any benefit in cash or kind, any hospitality, or any subsidy derived from any source that may have or be perceived to have an interest in the outcome of the review." ${ }^{4}$

The editors reserve the right to publish this information, or part of it, if they consider it important to evaluating the manuscript.

In the event that relationships exist that could signify a conflict of interests, the authors must specify what type of conflict exists and of what it consists. In addition, in the case that an investigation has received subsidies, "Authors should describe the role of the study sponsor(s), if any, in study design; in the collection, analysis, and interpretation of data; in the writing of the report; and in the decision to submit the report for publication. If the supporting source had no such involvement, the authors should so state."

Acknowledgments. In accordance with the guidelines of the International Committee of Medical Journal Editors, this section includes: ${ }^{2}$

a) collaborations that should be acknowledged but that do not justify authorship, such as the general support of the department head; $b$ ) technical help received; c) words of thanks for financial and material support, specifying the nature of that support; d) financial relations that may give rise to a conflict of interest.

Persons who collaborated intellectually but whose participation does not justify authorship may be cited by name, adding their function or type of collaboration; for example, "scientific adviser," "critical review of the study proposal," "collection of data," "participation in the clinical assay."

Authors must secure written authorization from the persons mentioned by name in the section on acknowledgments, as readers may infer that such persons support the data and conclusions. At all times the journal reserves the right to request such authorizations.

\section{F. References}

Bibliographical references will be presented on sheets separate from the text and should be numbered consecutively according to the sequence of their appearance in the text. The text itself will include only the corresponding Arabic reference number, printed in superscript.

References should adhere to the guidelines adopted by the U.S. National Library and by the Index Medicus. ${ }^{5-7}$ Titles of journals should be abbreviated according to 
the List of Journals Indexed in Index Medicus, published annually in the January issue of said index, or as indicated by the American National Standards Institute (ANSI). ${ }^{8}$

\section{Journal}

Journal references should include:

a) Family name(s) and initial(s) of given name(s) of the authors, followed by a period (list all authors if six or less; if seven or more, list only the first six followed by "et al."). The only punctuation to be used is commas to separate one author from another, as well as a period after the last author. If an author's two family names are to be given, they will be joined by a short hyphen.

b) Full title of the article, with capitalization of only the first letter of the initial word (and of proper names), followed by a period.

c) The journal's abbreviation, with no punctuation of its acronym or at the end.

d) Year of publication, followed by a semi-colon.

e) Volume number (in Arabic numerals), followed by a colon.

f) Page numbers (first and final) of the article, separated by a hyphen.

Examples:

Standard form

Martínez-Gutiérrez M, Alvarez-Jiménez E. El análisis de la población en México. Salud Publica Mex 1982; 24:286-294.

Anonymous

Epidemiology for primary public health care. Int J Epidemiol 1976;5:224-225.

Corporate author

Comité Internacional de Editores de Revistas Biomédicas. Nuevos Requisitos para la publicación de manuscritos en las revistas biomédicas. Rev Med IMSS 1981;19:119-125.

\section{Books and other reviews}

a) Family name(s) and initials of given names of the authors, followed by a period (list all authors if six or less; if seven or more, only the first six should be listed followed by "et al."). The only punctuation to be used are commas to separate one author from another, as well as a period after the last author. If an author's two family names are to be given, they will be joined by a short hyphen.

b) Title of book, with capitalization of only the first letter of the initial word, followed by a period.

c) Edition number, if other than the first, followed by a period.

d) City where published, followed by a colon; when more than one city is indicated as place of publication, the first city mentioned is used; the city's name may be translated into Spanish.

e) Publisher's name, followed by comma.

f) Year of publication (of the last edition cited if more than one), followed by a semicolon if the volume number is to be indicated, and by a colon if page number(s) is noted.

g) Number of volume if more than one, preceded by the word "vol.", followed by a colon.

h) Page number(s) of the particular citation; in referring to a book chapter, indicate the first and last page of the chapter, separated by a hyphen.

Examples:

Standard form

Alvarez JK, Mondragón L, Becerril A. El análisis general de la salud. 3rd edition. Madrid: Editorial Salvat, 1982;vol.6:518.

Corporate author

American Medical Association, Department of Drug. AMA drug evaluation. 3rd edition. Littleton: Publishing Sciences Groups, 1977.

Editor, compiler

Rhodes AJ, Van Rooyen CE, comp. Textbook of virology: For students and practitioners of medicine and the other health sciences. 5th edition. Baltimore: Williams \& Wilkins, 1968.

\section{Chapter of a book}

Weinstein L, Swartz MN. Pathogenic properties of invading microorganisms. In: Sodeman WA, comp. Pathologic physiology: Mechanisms of disease. Philadelphia: WB Saunders, 1974:457-472.

\section{Publication of an organization}

National Center for Health Statistics. Acute conditions: Incidence and associated disability, United States, July 1968-June 1969. Rockville (MD): National Center for Health Statistics, 1972. 


\section{Internet}

Online Journal article:

a) Family name(s) and initial(s) of given name(s) of the authors, followed by a period (mention all of the authors when less that six; when there are seven or more authors, indicate only the first six followed by "et al.") The only punctuation used is commas to separate one author from another, as well as a period after the last author. If two last names are to be mentioned, they should be joined by a hyphen.

b) Complete title of the article, using capitals only for the first letter of the initial word (and for proper names), followed by a period.

c) Journal abbreviation, without punctuation between the initials or at the end.

d) Add the legend "[internet series]"

e) Year of publication.

f) Date on which it was consulted between brackets (year, month, day) followed by a semicolon.

g) Volume, in Arabic numerals, followed by a colon.

h) Numbers of the first and last pages (when applicable) separated by a hyphen. In the event that page numbers are not clearly established, the approximate numbers may be added between brackets, followed by a period.

i) Webpage or website where the reference is found, preceded by the legend "Available in:" and followed by a period.

Example:

Abood S. Quality improvement initiative in nursing homes: the ANA acts in an advisor role. Am J Nurs [internet series] 2002 [consulted 2002 August 12]; 102(6): [approx. 3 pp]. Available in: http:/ / www.nursingworld.org/AJN/2002/june/ Wawatch.htm.

Online Monograph:

a) Family name(s) and initial(s) of given name(s) of the authors, followed by a period (mention all of the authors when less that six; when there are seven or more authors, indicate only the first six followed by "et al.") The only punctuation used is commas to separate one author from another, as well as a period after the last author. If two last names are to be mentioned, they should be joined by a hyphen.

b) Complete title of the article, using capitals only for the first letter of the initial word (and for proper names), followed by a period. c) Add the legend "[online monograph]" followed by a period.

d) City in which the work was published followed by a colon; when more than one place of publishing is indicated, use the one that appears first.

e) Publisher's name, followed by a comma.

f) Year of publication (of the latest edition cited if there is more than one).

g) Date on which it was consulted between brackets (year, month, day) followed by a semicolon if the volume is going to be indicated, and by a colon if the page numbers are stated.

h) Volume number if there is more than one, preceded by the abbreviation "vol." followed by a colon.

i) Numbers of the first and last pages (when applicable) separated by a hyphen. In the event that page numbers are not clearly established, the approximate numbers may be added between brackets, followed by a period.

j) Webpage or website where the reference is found, preceded by the legend "Available in:" and followed by a period.

Example:

Foley KM, Gerband H, eds. Improving palliative care for cancer [online monograph]. Washington, DC: National Academy Press, 2001 [consulted 2002 July 9]. Available in: http://www.nap.edu/ books $/ 0309074029 / \mathrm{html} /$.

Table 1 contains other examples for the correct presentation of references.

\section{G. Tables and figures}

Information to be given in tables should be presented double-spaced throughout in separate sheets of paper. Tables should be numbered in Roman numerals, in the same order in which they are mentioned in the text.

All tables should be self-explanatory, should be given a full title, although brief and concise; each column should carry headings at the top; notes and description of non-authorized abbreviations should be placed as a footer of the table, including clear indications of the measurements used. The use of vertical and horizontal lines should be omitted.

Figures should be numbered using Arabic numerals, in the same order in which they are mentioned in the text. Photographic reproductions should be high quality, clear, contrasted in black and white glossy printed. On the back of each photograph a label should be attached with the corresponding Arabic number, the title of the article, the name of the principal author, and 


\section{Table I}

\section{Presentation of references}

Articles in journals

(I) Standard article

You CH, Lee KY, Chey RY, Menguy R. Electrogastrographic study of patients with unexplained nausea, bloating and vomiting. Gastroenterology 1980;79:3|I-3|4.

(2) Corporation as author

The Royal Marsden Hospital Bone-marrow Transplantation Team. Failure of syngeneic bone-marrow graft without preconditioning in post-hepatitis marrow aplasia. Lancet 1977;2:742-744.

(3) No author

Coffee drinking and cancer of the pancreas (editorial). Br Med J 1981;283:628.

(4) Volume with supplement

Magni F, Rossoni G, Berti F. BN-5202I protects guinea-pig from heart anaphylaxis. Pharmacol Res Commun 1988;20 suppl 5:75-78.

(5) Issue without volume number

Baumesiter AA. Origins and control of stereotyped movements. Monogr Am Assoc Ment Defic 1978;(3): 353-384.

(6) Issue without number and without volume number Danoek K. Skiing in and through the history of medicine. Nord Medicinhist Arsb 1982:86-100.

Books and other publications

(7) Author

Colson $\mathrm{JH}$, ArmourWJ.Sports injuries and their treatment. 2nd edition. London, 1986.

(8) Editor(s) and compiler(s) as author(s)

Diener HC, Wilkinson M, ed. Drug-induced headache. New York: Springer-Verlag, 1988.

(9) Corporation

Virginia Law Foundation. The medical and legal implications of AIDS. Charlottesville:Virginia Law Foundation, 1987.

(I0) Chapter in book

Viter; F.The consequences of iron deficiency and anemia in pregnancy. In:Allen L, King J, Lönnerdal B, ed. Nutrient regulation during pregnancy, lactation and infant growth. Advances in experimental medicine and biology. New York: Plenum Press, 1994: I27-I39.

(II) Report presented at symposium

Harley NH. Comparing radon daughter dosimetric and risk models. En: Gammage RB, Kaye SV, ed. Indoor air and human health. Proceedings of the Seventh Life Sciences Symposium; 1984 Oct 29-32; Knoxville (TN), EUA.
(12) Thesis

Youssef NM. School adjustment of children with congenital heart disease (tesis). Pittsburgh (PA): University of Pittsburgh, 1988.

Online publications

(13) Online Journal article Díaz-Ortega J:, Meneses-Reyes CD, Palacios-Martínes M. Incidencia y patrones de transmisión de rubeola en México. Salud Publica Mex [internet series] 2007 [consulted 2007 December 17];49(5):337-347. Available in: http://www.insp.mx/rsp/articulos/ articulo.php?id=002086.

(14) Online monograph

Consejo Nacional de Población. Metodología de estimación del índice de marginación. Anexo C [online monograph]. Mexico:CONAP, 2005. [Consulted 2006 October]. Available in: http://www.conapo.gob.mx/ publicaciones/margina2005/anexo_c.pdf.

(I5) Web page o web site

Cancer-Pain.org [sitio de internet]. Nueva York: Association of Cancer Online Resources, Inc.; @2000-200I [actualizado 2002 mayo 16; consultado 2002 jul 9]. Disponible en: http://www.cancer-pain.org

(16) Web page o web site American Medical Association [sitio de internet]. Chicago:AMA; c19952002 [actualizado 200I ago 23; consultado 2002 ago I2].AMA Office of Group Practice Liaison; [aprox. 5 pantallas]. Disponible en: http://www. ama-assn.org/ama/pub/category/l736.html

Other publications

(17) Newspaper article Rensberg B, Specter B. CFCs may be destroyed by natural process. The Washington Post 1989 August 7; section A: 2 (col 5).

(18) Dictionary or similar references Ectasia. Dorland's illustrated medical dictionary. 27th edition. Philadelphia:WB Saunders, 1988:527.

(19) CD-ROM

Anderson SC, Poulsen KB.Anderson's electronic atlas of hematology [CD-ROM]. Philadelphia: Lippincott Williams \& Wilkins,2002.

Unpublished material

(20) Print pending

Material in-press should be listed as a footnote and not included among references:

Lillywhite HB, Donald JA. Pulmonary blood flow regulation in an aquatic snake. Science. Print pending. 
an indication noting the illustration's right side up. In the event that the images are electronic files, they should be accompanied by the corresponding data in order to be reproduced.

Each figure should be presented in a separate sheet, numbered sequentially, and should contain the title and the explanations of the symbols, arrows, numbers or letters used for identifying the different parts of the illustration. Both tables and figures should include source notes.

Tables and figures delivered in digital format must include a separate file (one for tables and one for figures), numbered as appropriate and in the correct sequence. These files may be in Word or Excel. In the event that the figures are to be treated as an image (for example, photographs and illustrations), they should have a resolution of $600 \mathrm{dpi}$ and be sent as a .tif or .jpg file, accompanied by text that explains which file corresponds to which figure. Figures that consist of graphics generated from data must be accompanied by that data in an editable Excel format.

\section{Randomized controlled clinical studies}

In the event that the work includes randomized controlled clinical studies, Salud Pública de México adheres to the CONSORT Declaration (Consolidated Standards of Reported Trials), which the medical journals adherent to SciElo agreed to adopt, at their Río Comité Consultivo meeting.

According to the CONSORT Statement: "To comprehend the results of a randomized controlled trial (RCT), readers must understand its design, conduct, analysis, and interpretation." ${ }^{\prime 9}$

In addition, the publication of an RCT is to clearly convey to readers why and how the study was conducted and analyzed.

In its original form, the CONSORT Statement was developed to "help authors improve reporting by use of a checklist and flow diagram. ${ }^{\prime \prime}$

As a result of the above, work that includes RCT and that is submitted to Salud Pública de México must utilize the 22 points and the CONSORT Statement Flow Diagram, which help to meet the indicated purpose. The pertinent information can be consulted at http:/ / www. consort-statement.org.

\section{Units of measure-International System of Units}

Units of weight and measure and physical units cited in the works must correspond to the International System of Units (IS) approved by the International Office of
Weights and Measurements and recommended for the health professions in WHA resolution 30.39, adopted by the Thirtieth World Health Assembly held in May of 1977.

Several rules and specifications exist regarding the use of the IS symbology: ${ }^{10,11}$

- For symbols or abbreviations, lowercase is recommended; some exceptions are: the $\mathrm{K}$ for the Kelvin unit of temperature and the A for the unit of electric current, the ampere; in the case of the later the symbol can be both 1 or $L$; this unit is not registered in the IS, but is frequently used in the area of health.

- No symbol should be followed by a period (.), unless the symbol is at the end of a sentence.

- No symbol should be expressed in the plural, all symbols will be in the singular ( $\mathrm{kg}, \mathrm{m}, \mathrm{mg})$.

- When numbers are used, they must be followed by their symbol and set apart by a space between each other (100 m, $3 \mathrm{~mol}, 50 \mathrm{ml})$.

\section{Publication of the accepted article}

Once the article is accepted for publishing, the editor reserves the right to make formal modifications that he considers appropriate to achieve greater uniformity and clarity in the presentation of the work.

After the journal is published, the author will receive 20 copies of the article.

\section{Acknowledgments}

The original authorship of this work was headed by Octavio Gómez Dantés, M.D., and appeared for the first time in 1988 in this journal. Since 1992, valuable contributions, made by Lucila Pacheco Peña, M.D. -who was the general editor of Salud Pública de México until 1995- have been incorporated. They have our highest recognition for their important professional work in this journal.

\section{References}

I. Frenk J. La nueva salud pública. In: Instituto Nacional de Salud Pública 1987-1991. Cuernavaca, México: INSP, 1992.

2. International Committee of Medical Journal Editors. Uniform requirements for manuscripts submitted to biomedical journals. Ann Intern Med 1988; 108:258-265.

3. International Committee of Medical Journal Editors. Uniform requirements for manuscripts submitted to biomedical journals: Writing and editing for biomedical publication. [Consulted: June 2007] Available in: http://www. icmje.org/

4.The Cochrane Collaboration. The Cochrane Manual Issue 3,2007 [updated 24 May 2007]. [Consulted:June 2007] Available in:http://www.cochrane.org/ admin/manual.htm. 
5. International Steering Committee. Uniform requirements for manuscripts submitted to biomedical journals. Ann Intern Med 1979;90:95-99.

6. Huth E. New form for references. Br Med J 1979; I: I697-1698.

7. Huth E. Medical style \& format. An international manual for authors, editors, and publishers. Philadelphia, PA: ISI Press, 1987.

8. American National Standards for Information Sciences. Abbreviation of titles of publications. New York:ANSI, 1986.

9. Moher D, Schulz KF,Altman DG, CONSORT Group (Consolidated Standards of Reporting Trials).The CONSORT statement: revised recommen- dations for improving the quality of reports of parallel-group randomized trials. [Consulted January 2008] Available in: http://www.ncbi.nlm.nih.gov/ pubmed/I I574648?.ordinalpos= I \&itool=Entrez System2.PEntrez.Pubmed. Pubmed_ResultsPanel.Pubmed_RVDocSum

I0. Velázquez-Jones L, Llópiz-Avilés M. El Sistema Internacional de Unidades en la investigación y la práctica clínica. Bol Med Hosp Infant Mex 1987;44:369-372.

II. Llópiz-Avilés M, Gómez-Dantés O. El Sistema Internacional de Unidades. Salud Publica Mex 1988;30:905-908. 